\title{
Collaborative Production and the Transformation of Publishing: The Case of Wattpad
}

\author{
Rosamund Davies \\ University of Greenwich
}

Collaborative production is another way to describe what Bauwens terms peer-to-peer ( $\mathrm{P} 2 \mathrm{P})$ production, whereby $\mathrm{P} 2 \mathrm{P}$ collaborators work together to construct a shared commons and use value (Bauwens, 2005). This approach to production has been enabled on a large scale by the widespread availability, low cost and connectivity of digital technologies (Bauwens, 2005, Benkler, 2006). Examples of such practices might include the open software movement, crowdsourcing and crowdfunding initiatives, MMOGs (massively multiplayer online games) and fandoms, among others. Although the core aims and values of collaborative production and its products are generally understood to be non-market based, many of its manifestations are interdependent with the market-based economy (Bauwens, 2005, Benkler, 2006, Jenkins, 2013, Arvidsson, 2013), as we shall go on to examine.

The social reading and writing platform, Wattpad, offers a fairly recent example of such collaborative production. Wattpad is a digital enterprise, founded in

How to cite this book chapter:

Davies, R. 2017. Collaborative Production and the Transformation of Publishing:

The Case of Wattpad. In: Graham, J. and Gandini, A. (eds.). Collaborative

Production in the Creative Industries. Pp. 51-67. London: University of

Westminster Press. DOI: https://doi.org/10.16997/book4.d. License: CC-BY-NC-

ND 4.0 
2008 in Canada, but with a global user base of 40 million at the time of writing (Wattpad, 2016a). Around 80 per cent of this user base is 30 years old or under (around 40 per cent 13-17 and 40 per cent 18-30 year olds) (Wattpad, 2016f). At the time of writing, Wattpad is free to join and offers its members a digital platform for both reading and writing. Although it does offer conventionally published works that are out of copyright, Wattpad users mainly read and contribute to stories written by other users. Ninety per cent of interaction with the site is through mobile use (Wattpad, 2016a). Common practice on the site is for writers to serialise their stories, uploading one or two chapters at a time and inviting comment and discussion on each chapter. New users are encouraged to follow this practice (Wattpad, 2016b). 'Wattpaders', as they are known, can also follow each other's profiles and join clubs (discussion forums) focused on particular genres or other aspects of reading and writing. There are also forms of collaborative writing, such as role-playing games. Some readers set up curation profiles, offering curated selections of works in a particular genre or otherwise defined category, e.g. short stories, YA, fan fiction, diversity, literary fiction. Wattpad has become particularly well known as a source of fan fiction, of which 13 million hours worth was read by users in 2014 (Anderson, 2015).

In the following pages, I will consider Wattpad as a community of readers and writers engaging in a process of creative dialogue and collaborative production of a shared commons and also as a transactional marketplace in which these readers and writers engage in the creation and circulation of value and exchange of services. In doing so, I will draw on existing debates relating to collaborative production.

These debates return frequently to the relationship and tensions between the potential social, political and economic roles of collaborative production. Bauwens explicitly distinguishes $\mathrm{P} 2 \mathrm{P}$ commons-based exchange from market exchange, which is concerned with exchange value and individual profit. However his analysis of the contemporary situation is that the two are currently interdependent. 'Netarchists' (Bauwens, 2005, n.p), such as Amazon and eBay, profit from peer collaboration by building platforms to enable it and monetize the value created in various ways. It is not currently possible for P2P producers to earn a living from $\mathrm{P} 2 \mathrm{P}$ production independently of these structures, although Bauwens' hope is that $\mathrm{P} 2 \mathrm{P}$ production may ultimately transcend market capitalism. Benkler (2006) identifies non-market collaborative production as a rising force within the 'networked information economy' (Benkler, 2006, p. 4), which is 'reshaping the market conditions under which businesses operate' (Benkler, 2006, p. 24). At the same time, he cautions that concerted social and political action will be needed (and is yet unforthcoming) to fully realise the social, political and economic possibilities opened up by these new material conditions of production (Benkler, 2006).

Writing half a decade later, Rachel Botsman is a passionate advocate of the transformative potential of what she terms the rise of 'Collaborative Consumption'. Botsman and Rogers (2011) enumerates multiple examples 
of how a new relationship between market and community values has been successfully forged in new types of organisation that have emerged, based on the model of peer-to-peer collaboration and sharing. Citing both large commercial companies such as Airbnb and non-commercial and small initiatives, such as time banks and barter-based community markets, the authors identify a 'socioeconomic groundswell' in which 'the old stigmatized C's associated with coming together and sharing - cooperatives, collectives, and communes - are being refreshed and reinvented into appealing and valuable forms of collaboration and community.' (Botsman and Rogers 2011, n.p) Botsman envisages collaborative consumption markets as offering a contemporary version of the kind of trust-based exchange characteristic of traditional communities.

Jenkins (2013), however, problematises the relationship between market and community values in contemporary networked culture, focusing particularly on media production. Drawing on the idea of a 'moral economy', based on wider social norms, which governs business transactions within a particular society (E. P. Thompson, 1971, in Jenkins, 2013), Jenkins suggests that the digital networked economy has caused a crisis in the contemporary moral economy, creating new contexts in which goods and services are produced and exchanged, such as peer-to-peer sharing and production (Jenkins, 2013). Uncertainty and disagreement over the extent to which such contexts assign market or nonmarket values to these goods and services has eroded established bases for trust and mutual understanding. This uncertainty relates both to the activities of companies whose business model is based on monetizing collaborative production and consumption and also to the ways in which traditional media producers are starting to engage with fans. When value creation is shared between producers and consumers, those very terms are called into question, as is our understanding of the separation between commodity and gift economies (Jenkins, 2013). We are at present still developing a language with which to discuss and understand these new conditions of production and exchange.

As Botsman's account demonstrates, a term that has come to the fore, as we try to develop such a language, is 'community'. Corporations and marketers across all sectors of the economy have seized on the concept of 'community building' as a strategy they need to embrace, in order to encourage consumer loyalty and monetise consumer attention (Jenkins, 2013). However, while 'brand communities' have become a valuable commercial asset, they are not actually owned by the brand in any straightforward way, since their value is created through the autonomous participation of the members of the community. As the networked economy becomes more and more dependent on this process of shared value creation, there is the potential for such communities to exert significant economic pressure (Jenkins, 2013, Arvidsson, 2013, Balaram, 2016) and, furthermore, to function as 'productive consumer publics' - exerting not only economic but wider social and political influence (Arvidsson 2013).

This chapter will explore the ways in which these kinds of tensions and potentials in the interrelations between market and non-market values and 
activities, between communities, markets and publics, characterise the operations of Wattpad. The aim will be to understand more about the nature of collaborative production on Wattpad and also to consider the model it might offer for the transformation of creative and business practices within writing and publishing.

According to Wattpad's Head of Content, Ashleigh Gardner, 'Wattpad is a social network and not a publishing platform.' (Gardner, 2014) She points out that 90 per cent of Wattpad's users are readers, compared to 10 per cent who are writers (Gardner, 2014). As outlined above, these readers use the site not only to access content to read, but to engage in discussion with the writers they read and also with other readers. Thus, as a platform, Wattpad's aim, similar to that of Facebook, YouTube and others, is to facilitate the creation of content in order for that content to generate interactions between users and so build a community.

Although the terms 'social network' and 'community' are often used interchangeably, Owens (2014) draws a distinction between an online community as a virtual place 'in which people come together around shared interests' and a social network in which the individual user is 'a node, as an object, that is networked and connected to other users based on features of their profile.' (Owens, 2014, p. 94) One key implication of this distinction is a greater emphasis on collective experience in the community and on a customised individual experience in the network. In the social network, the status of the individual is increased by the number of links he or she has with other individuals in the network (Boltanski and Chiapello, 2005), rather than by his or her contribution to the common aims and objectives of a community as a whole.

In contemporary online culture most of what are referred to as communities are in fact structured as social networks. This fact is closely linked to the network's ability to function as a market and to the monetization opportunities it offers to the organisation that hosts it. Individual profiles linked in a network can be quantified, analysed and leveraged not only by the individuals themselves, but also by the host organisation, which is able to sell both their community's attention and their data to advertisers and other third parties.

Wattpad would seem in fact to offer both versions. It is a community of interest focused on writing and reading and its clubs offer a version of old style online community engagement as defined by Owens: where Wattpaders raise and discuss ideas and concerns of common interest to the community. At the same time, Wattpad's structure of individual user profiles provides the basis for a social network.

Before going further into an analysis of how Wattpad's social network structure enables its function as a marketplace and as a monetisable asset for its owners, I want to bring the concept of the 'public' into the discussion, turning first to boyd's (2014) discussion of teenage networked publics.

Beyond spending time with their friends in private spaces, such as each other's homes, teenagers feel the need to gather together in public. In the physical world, spaces such as shopping malls and public parks continue to attract teens 
as places to gather. Social media offer them a further public space in which to congregate. According to boyd (2014) 'teens engage with networked publics for the same reasons they have always relished publics; they want to be a part of the broader world by connecting with other people and having the freedom of mobility... social media services like Facebook and Twitter are providing teens with new opportunities to participate in public life.'(p. 10)

boyd stresses that, in seeking public spaces in which they can appear and express themselves, teenagers are looking for more than a chance to socialise with their peers. Although social networks may work by linking one individual with another, these connections and much of the interaction they generate are public. Teens seek public engagement and recognition as an important part of developing from child to adult. She stresses the symbolic importance of doing something in public as opposed to in a purely private realm of activity. boyd goes on to point out, however, that when teenagers do attempt to participate in wider public life through political action, such as public protests, they are, like other minority or underrepresented groups, often dismissed as irrelevant or attacked as irresponsible. Social media offer teenagers a 'youth-centric public space' (boyd, 2014, p. 19) that may not exist elsewhere.

If society is made up of 'a whole host of publics' (boyd, 2014, p.202), then we might understand teenagers using social networks to be participating in their own 'intimate publics'. The term 'intimate public' was developed by Berlant as part of her critique of the general 'privatisation of citizenship' (Berlant, 1997, p. 3) in the United States, resulting in the lack of a genuine public sphere in contemporary society. Berlant goes on to discuss the specific exclusion of minorities from political recognition and agency in whatever might remain of a political public sphere and how, in response to this exclusion, the intimate public legitimates qualities, ways of being, and entire lives that have otherwise been deemed puny or discarded' (Berlant, 2008, p. 3). Berlant's particular focus is on 'women's culture' as 'the first mass cultural intimate public' (Berlant, 2008, p. viii). Her enquiry is into the way that women gain a sense of belonging and community through the consumption of literature by and for women. According to Berlant, 'intimate publics elaborate themselves around a commodity culture... organized by fantasies of transcending, dissolving or refunctioning the obstacles that shape their historical condition.' (Berlant, 2008, p. 8)

The notion of the 'intimate public' provides a fruitful perspective from which to consider Wattpad, which has gained a reputation for being the reading site of choice for 13-18-year-old-girls, many of whom discover it through reading and writing fan fiction, which makes up a large volume of content on the site. The creation of fan fiction has been recognised as a way for young women to 'narratively experiment with gender roles, primarily by casting young females as protagonists, and to participate in ongoing exchanges related to themes and concerns from their lives' (Black 2008, p. 50). Wattpad's dominant demographic also explains the predominance of teen fiction and other teen popular genres such as romance and fantasy. 
Former Wattpad user, Hazal Kirci, writes that her experience of Wattpad was that it offered a safe and inspiring space for young women. Through it she was able to gain a sense of belonging, as well as be inspired to creative expression (Kirci, 2014). If intimate publics offer individuals 'a way of experiencing one's own story as part of something social' (Berlant, 1997, p.3), then the particular power of teen fiction on Wattpad, as opposed to commercially published YA literature, of which there is no shortage, is that not only does it provide stories that relate to the key issues in its readers' lives, but, like fan fiction in general, it also provides readers and writers with the chance to interact with each other as part of an ongoing exchange between peers and feel part of a community.

In her more recent discussion of intimate publics, however, Berlant (2008) states that the 'juxtapolitical' relationship of intimate publics to the political process is often problematic, since, while they offer a refuge from political injustice, oppression or lack of recognition, they may struggle to impact on broader publics that carry greater social and political legitimacy and weight.

In the case of women's literature, for example, readers often realise a sense of self and of social belonging through the conventional plot of romance, which resolves real life problems through fantasy (Berlant, 2008). While this may help women to endure real life injustices, it may not necessarily inspire women to challenge them. Even if they do, in wider society 'womens' issues' are too often treated as personal concerns rather than as matters of general public and political significance.

Although he does not himself reference either writer, Arvidsson's discussion of 'productive publics' (Arvidsson 2013, p. 381) has relevance to our consideration of the 'networked publics' identified by boyd and the 'intimate publics' discussed by Berlant, since the social and political aims and impact of particular 'publics' are central to the arguments of all three writers. Arvidsson specifically promotes the term 'public' over 'community' for the stated reason that the term 'community' within social theory involves direct interaction between members, founded upon 'actually existing social relations that really work as foundations of trust and mutual support.' (Arvidsson, 2013, p. 377) For Arvidsson, a large-scale structure of communication and experience of communality involves common interests and pursuits amongst a group of people who may contribute to a common pool of resources, yet it does not necessitate, or indeed facilitate, actual co-creation or direct interaction between all members. Such structures should not, therefore, be described as communities, but rather as publics.

There is a related point to make here, which is that members of a 'public' face outwards, towards an external object of attention, whether that be a cultural artefact, a commodity or a national government, while communities might be seen as inward facing, concerned largely with maintaining their own networks. This might explain the frequency with which the term 'community' appears in the rhetoric of politicians. Although it may represent an attempt to acknowledge and legitimise particular interest groups, it equally offers a means (intentional 
or otherwise) of relativizing and controlling the representation within political debate of certain collective interests, by relocating them from the realms of politics or economics and into a putatively separate social realm. This results in a failure to properly address those interests (Plant, 1990, Preston, 2005).

The use of the term 'community' may therefore enact through language the kind of bracketing off of intimate publics from the wider political sphere that concerns Berlant. It is likely, I would venture, that this tendency is also a contributing factor to Arvidsson's explicit argument in favour of the term 'public' over 'community'. Likewise, although boyd and Berlant do use the term 'community' from time to time and in particular when discussing internal relations within a particular networked or intimate public, their use of the term 'public' is bound up with their interest in the social and political influence of such communities.

Having considered how Wattpad functions as a community and as an intimate public, it therefore seems pertinent to also consider whether the activities and concerns of this community have any wider public impact.

Kirci (cited above) moved on from Wattpad to join the Social Mobility Foundation's aspiring professionals programme and to write an article in The Guardian. While this example of individual aspiration might fall short of the kind of collective political engagement and impact envisaged by Berlant, Kirci certainly makes an explicit and more general connection between participation in Wattpad and increased literacy and academic engagement (Kirci, 2014), as does writer Margaret Atwood, an early and avid Wattpad supporter. Atwood argues, furthermore, that Wattpad encourages both writing and reading and that literacy is vital to the future of democracy (Atwood, 2012). A further example of the way in which participation on Wattpad might provide a means for young women to exercise political agency is Emily Lindin's The Unslut Project (Lindin, 2013, Wattpad, 2016b). A memoir of Lindin's traumatic experience of being labelled the 'school slut' age 11, this story gained a large readership on Wattpad and was subsequently published. Lindin also went on to make a related documentary and continues to raise awareness of and campaign against the cruel and bizarre practice of 'slut shaming' through The Unslut Project website. Wattpad therefore clearly has the potential to provide its community, or communities, of predominantly teenage and young women with a public forum and launch pad, from which to impact on a wider public.

However, in its current phase of development, Wattpad's market potential is becoming ever more apparent. At a microeconomic level, barter and exchange of services are much in evidence on the platform. For example, some Wattpaders produce covers for writers. In return, writers may follow them, or read and comment on their story. Such exchanges are acknowledged in comments, such as the message left by a Wattpader on another Wattpader's first chapter ' $\mathrm{Hi}$ there! I'm here as payment for my cover... Good luck on the rest of the rewrite' ('Wilting Hope', 2015). A further form of reciprocal recognition that Wattpaders can provide is to include each others' work in a reading list. These reading 
lists are featured on people's profile pages and are a form of recommendation, which will drive further readers to the featured stories.

The most widespread form of direct reciprocity, however, is through users reading and voting for each others' work and following each others' profiles. This is where we see the significance of Wattpad's structure as a social network of connections, which can be leveraged by individuals to increase their status within this network. Every follow and read of every chapter of every story is logged and the total displayed publicly on the user's profile. Furthermore, Wattpad readers can also vote for each chapter of a story, signifying not only that they have read it, but that they actively liked it. This establishes a link between reader and writer since writers are notified of the identities of those who vote on their story. If the writer recognises the reader back, by following him or her, the reader is then brought to the attention of the writer's followers. Both votes and reads, are totted up and added to the writer's vital statistics, which are displayed on his or her profile.

This process of mutual self-promotion has been described as a 'Social Ponzi scheme that works because nobody gets scammed' (Romano, 2012). The vote might perhaps be identified as the unit of exchange that comes closest to a form of currency within Wattpad. One could say that readers pay writers with votes. This process does not, however, establish a market price. A story does not become more 'expensive' for a reader to read when it has more votes. Rather, it becomes an increasingly effective hub for shared value creation by both reader and writer. In this regard Wattpad functions as an attention economy. The more attention you get, the more attention you generate. Voting is not a one-way process of recognition.

Direct reciprocity, however, is not the full story. Much of the interaction that takes place on Wattpad takes the form of indirect reciprocity, a feature common to other digitally networked sites of collaborative production and consumption (Bauwens, 2005, Botsman, 2011). As Arvidsson (2013) explains, publics will tend to abide by a particular ethos, 'a set of standards and expectations that allow members of that public to make judgements as to the value of the conduct and character of other members, or other publics' (p. 379). In the case of Wattpad, Wattpaders are expected to demonstrate commitment to the activity of reading and commentary. If you do not read, vote and comment on other people's work, if you do not participate and comment in members clubs, if you do not build your network, you are unlikely to get many readers for your stories (Wattpad, 2016c, Wattpad, 2016d). Beyond straightforward tit for tat exchange of attention between individuals, Wattpaders are expected to make a more general contribution to demonstrate that they uphold Wattpad's values. In return they will render themselves a visible and valued member of the community. To be recognised as a writer, you must therefore also be recognised as a reader.

Despite the functional importance of reading on Wattpad, being legitimated as a writer is a key means of increasing one's social capital and reputation in this economy. Once value has been created and expressed in the form of reads, 
votes and followers, this social/reputational capital is likely to start to generate more and more capital, requiring less and less labour on the part of its owner. Reads and votes can expand exponentially into the millions and far beyond any direct relationship of reciprocity. As Arvidsson (2013) has pointed out, 'publics create new values, in the form of 'buzz', reputation and opinion' (p. 376) and 'reputation is the form that social capital takes among strangers'. (p. 380) Once a Wattpad story has gained a certain number of reads and votes and the writer has thousands of followers, he or she is no longer operating in a social network of direct reciprocity but has established a public reputation as an exceptional Wattpader, evident to Wattpad members who have never interacted with the writer or his or her work. This is likely to attract more readers and generate ever more reads and votes for the work.

There is then a further level of value that can be generated. Reputational capital amassed on Wattpad can be converted to monetary value in the form of book, film and television deals in the conventional media marketplace. Wattpad writers have had particular success in the Philippines where several books have been published based on Wattpad stories (Gardner, 2014). According to Wattpad co-founder, Allen Lau, this phenomenon can be partly attributed to the combination of a highly literate population, interested in both reading and writing, and partly to the lack of developed publishing outlets in the Philippines (Lau, 2013). These factors led to huge interest in and use of Wattpad in the Philippines and the fast emergence of Wattpad 'stars'. Films and TV series followed, including the series Wattpad Presents, a partnership between Wattpad and television station Kapatid TV5 (Gardner, 2014, Tomada, 2014).

British and American teen writers have also translated their popularity on Wattpad into mainstream success. These include Beth Reekles, whose story The Kissing Booth, was published by Random House (Kirci, 2014) and Anna Todd, whose One Direction fan fiction story, After, was published by Simon \& Schuster and is being adapted into a film for Paramount Pictures (Hipes, 2015).

Even when Wattpad writers become Wattpad celebrities, however, they still belong to their community. Traditional conceptions of fame or becoming a 'star' might involve the idea of leaving one's roots behind. This is not the Wattpad model. As with celebrity YouTubers, fans feel a strong personal connection with these celebrities, whose continued success depends on their ability to maintain this connection with their fans (Burgess and Green, 2009). Todd is therefore developing her own app to keep in touch with her fan community and to encourage their contributions to her current work. Sam Rogoway, CEO of Victorious, the talent agency which represents Todd, makes the point that 'fans are not just consumers: they are creators in their own right, and they want to interact not just with the creators but with other fans.' (Dredge, 2015, n.p). Arvidsson (2013) identifies this type of expanded community as a 'productive consumer public' with the power to 'set the values that are attributed to consumer brands' (p. 385). Digital media celebrities function as the lynchpin of a community or network which they need to curate in line with their fans' expectations. 
Meanwhile, Wattpad stars fit easily into the trend towards celebrity authors within contemporary trade publishing. In this consolidated marketplace, driven by a logic of growth, the focus is on short term high returns delivered by bestsellers (Thompson, 2012). Publishers are looking to commission and develop authors with as a 'platform' (Thompson, 2012, p. 87), i.e. a visible public presence that can attract a loyal audience that will translate into high sales figures. A further advantage is that such an audience is likely to buy not just one book, but all the author's books.

An additional reason for the increasing focus on 'platform' is that, as more and more books are produced independently (self published), without the traditional gatekeepers, reader attention is the vital currency that both traditional and independent publishers need to access and convert into monetary value. In order to achieve this conversion, they need to reward this attention with an experience of belonging and validation. Authors are therefore under pressure to engage with their audience by spending 'three or four months a year doing the literary circuit full-time' (Groskop, 2014/15, p. 9), including appearing at literary festivals, which increase in number year on year. Publishers also attempt to connect with the reading public by organizing live events, such as readings, and facilitating book groups with a range of resources (see Bloomsbury, Penguin). Since Wattpad writers bring with them large and fully engaged communities, it is not hard to understand why Wattpad writers are so appealing to publishers. While political influence might depend on a community's ability to organise itself as a public, commercial success depends more and more on converting a public into a community.

As a commercial enterprise, Wattpad's business model is, like that of many other digital social networks, to monetise its community by selling its attention, its data and also its creative services to other businesses. Wattpad's relationship with the band One Direction has been particularly fruitful in this regard. One Direction fan fiction dominates Wattpad's fan fiction pages and, prior to One Direction's US debut, their label, Sony, commissioned a Wattpad fan fiction with the same title as the debut single. This partnership raised the profile of both band and writing platform (Romano, 2012).

Wattpad has also developed relationships with established authors, including Margaret Atwood, Paulo Coelho and Dan Brown, who all have a presence on Wattpad and independent (self-published) authors also use Wattpad as an additional channel and community-building platform.

Another focus is on developing 'native marketing' campaigns for brand owners, including Unilever and Apple (Wattpad, 2016f), and Wattpad recently signed a deal with talent and literary agency UTA to represent them in developing further partnerships and licensing opportunities (Hipes, 2015). The deal with UTA consolidates and develops Wattpad's existing business strategy, which Lau has described as concentrated on two main revenue streams: content marketing and content licensing, with marketing the primary and licensing the secondary focus (Nawotka, 2015). 
As I hope the above discussion makes clear, Wattpad offers a particular case study of the many ways in which, in the networked information economy (Benkler 2006), communities, markets and publics are inextricably linked together in complex networks of attention and sharing, which may be configured in various ways and for various purposes, including both interpersonal and commodity exchange. People engage in these relations and activities for a variety of overlapping aims: notably, but not exclusively, identity construction, belonging, social status and financial gain.

Some Wattpaders definitely see the platform as a stepping-stone to a traditional publishing deal or self-publishing venture. Others are less focused on professionalization of their activity and value it primarily as an outlet for creative self-expression, social interaction and validation. As well as providing a safe community, Wattpad allows users to feel that they are part of public life and contributing to a wider conversation.

Like most communities, Wattpad also facilitates barter of services amongst members. It functions as a marketplace for reciprocal exchange as well as a peer production economy based on indirect reciprocity and contribution to a shared commons (Bauwens, 2005). However Wattpad's system of votes and reads also facilitates a more capitalistic type of activity, in which it is possible and indeed desirable to accumulate reputational capital in order to gain a higher social status beyond one's immediate community of readers and writers. It is then possible for such Wattpad public celebrities to convert this reputational capital into financial gain. While Wattpad is therefore most definitely a site of economic activity, I would argue that this is not incompatible with or indeed separable from ways it might be seen to function as a community. Indeed, the continued success of Wattpad star writers is closely bound up with the continued loyalty of their fan community.

As Arvidsson (2013) points out, what is emerging here is 'a new paradigm of value that is both ethical and economic at the same time' (p. 385). Fan communities function as publics to the extent that they draw on their shared community values to exert influence on the object of attention that has originally brought them together. While this object of attention may originally have been a media text or a brand or a celebrity, as a community builds around it, the community itself, the shared values it develops and the active participation of community members become part of the object of attention and part of its economic value. It becomes impossible to separate ethical and economic value at this point. Fans are not only adding value, they are actively determining what that value is. When a publisher commissions a Wattpad writer they are not just signing up a writer or buying a commodity to distribute, they are entering into a relationship with a 'productive consumer public'.

Wattpad itself has the same considerations, now that, having established critical mass, it moves towards a great focus on monetization as the self-proclaimed 'YouTube of Stories' (Powell, 2013). It will inevitably become more commercialised. However, like YouTube, Wattpad's economic value will continue to 
depend on its ability to successfully maintain its function as a community/ intimate public, to satisfy the expectations of that public and further its aims. Ideally Wattpad would fulfill the function that Botsman assigns to collaborative production and consumption platforms, where the role of this new intermediary is therefore to create the right tools and environment for familiarity and trust to be built, a middle ground where commerce and community meet.' (Botsman, 2011 n.p)

What implications might Wattpad's business model have for traditional publishing? As discussed above, Wattpad's model of value creation is demonstrably interoperable with that of commercial publishing. Like YouTube, Tumblr and Instagram, Wattpad facilitates the feedback loop between audiences, 'prosumers' and professional producers. Traditional publishing feeds into Wattpad, just as Wattpad feeds into traditional publishing. The interests of readers and writers on Wattpad have been shaped in part by the recent explosion in YA fiction in publishing, as well as by developments in fan fiction. Wattpad readers' enthusiasm for peer-produced content therefore presents no threat to professional publishing. On the contrary, it offers publishers access to a large audience base and talent pool.

I would suggest that Wattpad also offers a potential model of how writing, reading and publishing might more generally develop as part of the networked information economy. Networked digital technologies make visible the fact that audiences not only want to own content they also want to share it with others, in order both to build relationships and to participate in collective identities. This process of sharing can involve a range of activities, including discussion, modification and co-creation of content. As these processes become more visible as part of a public conversation across digital platforms with millions of users, they attract more people to participate in them. Consequently modes of engagement that were previously considered to be the 'cult' behaviours of fans have now become more mainstream (Jenkins, 2013).

Such modes of engagement could perhaps be more fully catered for by publishers through alternative forms of content and delivery to the traditional form of the book: short form and/or serialized content, for instance, which can be easily shared and discussed; or transmedia approaches to storytelling, which encourage immersive and long term engagement with story worlds. The problem for publishers is that, to be commercially successful, such approaches might well necessitate different business models. Serialised content might better suit a subscription model, for example, while transmedia storytelling would require publishers to hold onto and exploit for themselves adaptation rights that they currently license to other media companies. As long as the book remains viable as the primary unit of value, there is no great incentive for commercial trade publishers to make such leaps into the unknown.

Nevertheless, the big publishers are cautiously exploring new approaches. Orion's recent publication Belgravia, written by Julian Fellowes is one such example (Martin, 2016), as is the ongoing discussion in the industry as to the 
pros and cons of subscription (Campbell, 2015). However, it is currently smaller publishers who are most evidently developing alternative business models that share some of the principles of collaborative production. They often focus on subscription as a revenue stream, for example, rather than on individual book sales (e.g. Salt, And Other Stories, Peirene Press, Galley Beggar Press), developing a relationship with their readers that is not one of commodity exchange so much as one of shared value creation, in which all parties are collaborators in the shared project of keeping the press running and getting the books published (see Graham, in this volume, for further discussion of this trend).

This model could of course be seen as extremely old, rather than new, since subscription to publications was prevalent in the eighteenth century. However networked digital culture makes it much easier for small publishers to connect with their readers and to maintain and strengthen the sense of community, as well as to keep their overheads low. It also facilitates an alternative collaborative approach in the form of crowdfunding, via platforms such as Kickstarter on which publishing is the third most popular category (Phillips (2016) and Patreon.

Crowd funded publishing often engages supporters not only in funding, but in creating content. Therefore, although the process may end in the stable and familiar form of a completed book, participation in the process of production itself is part of the value proposition and indeed may be of more value to participants than the final product itself. The design of this participation by the project's initiators becomes as important to the project's success as the design of the final product. In such a context, writers and publishers need to adopt a substantially different approach to production than that of conventional publishing. Not only are they curating a community in the same way as the Wattpad stars discussed above, they are designing an experience as much as a product and are very often offering readers a text that is still unfinished, open to input and potentially multifaceted.

To sum up the above discussion, we might therefore conclude that, in the current moment within publishing, we are seeing signs of a potential transformation of the sector, in line with the transformative potential of collaborative production identified by commentators such as Benkler, Botsman, Jenkins and Arvidsson.

Although mainstream publishing is moving only slowly in this direction, developments in alternative publishing contexts demonstrate ways in which it might be achieved.

The networked information economy constitutes a 'technological-economic feasibility space' (Benkler, 2006, p. 3) within which the market value of communities continues to rise, in tandem with a renewed understanding of the value of non-market activities to communities and to society in general. This is a delicate balance. While it is likely that commercial logic will eventually take mainstream publishing towards a business model of shared value creation, it is to be hoped that such developments will not crowd out alternative and smaller 
publishers, who have currently found a new space to operate. Rather, collaborative production has the potential to sustain alternative publishing approaches and give them a stronger market and cultural presence.

As people witness and participate in the large-scale public conversation and collaborative production enabled by digital technologies, they not only form communities of interest but also conceive of themselves as publics, who can and should exert influence. This is why Arvidsson envisages 'productive consumer publics' to have the potential to 'represent a new institutional form in which the spheres of economics, ethics and politics, tragically separated in the modernization process, come together in forms of public action' (Arvidsson, 2013 , p. 35). Such public action will be necessary, since the 'spirit of capitalism' is mutable (Boltanski and Chiapello, 2005), even as its underlying logic of accumulation and reinvestment of capital remains constant. It is possible for a discourse of community to be instrumentalised and exploited within economic theory and practice in the same way as discourses around creativity (Boltanski and Chiapello, 2005, Brouillette, 2014) and well-being (Davies 2015). Meanwhile, the same imperative of growth and ROI for shareholders that drives contemporary commercial publishing frequently compels potential collaborative production entrepreneurs to 'pivot' away from a business model of shared value towards maximum value extraction, once they obtain capital investment (Rushkoff in Troncoso, 2016).

In order to establish a new moral economy to regulate these new conditions of production and exchange, 'productive consumer publics' will need to exert influence not only on businesses but on political and legal institutions to establish the kind of network and regulatory infrastructure (Benkler, 2006) in which they can function most productively.

Questions to explore beyond this chapter with regard to publishing include:

- The future role of publishers - Will the role of publisher move closer to that of community manager? How might the operations of online book distributors, such as Kobo and Amazon, and indeed platforms such as Wattpad, impact on or perhaps merge with those of publishers? - Alternative marketplaces - Might the new space of publishing that is emerging offer alternative marketplaces for reading and writing? Might current crowdfunding platforms, for instance, evolve to provide such marketplaces, beyond what they are doing at the moment, perhaps in tandem with small, independent publishing outlets? What might be their distinctive features?

- The use-value of writing and reading - The end game for writers may not always be to publish, to achieve some kind of commercial success or public impact. How is non-market peer-to-peer writing and reading developing as a cultural activity and how might it develop in the future? 
- What specific structures and approaches might support collaborative writing and reading publics in achieving the kind of social and political impact that Arvidsson envisages? The suggestions of theorists such as Hind (2010) and Couldry (2010) provide a starting point for further research.

\section{References}

Anderson, P. (2015). Digital writing: If only community weren't so communal. The Bookseller, 4 August. Retrieved from http://www.thebookseller.com/ futurebook/if-only-community-werent-so-communal-308390.

Arvidsson, A. (2013). The potential of consumer publics. Ephemera: Theory \& Politics in Organization, 13(2), 367-91.

Atwood, M. (2012). Why Wattpad works. The Guardian, 6 July . Retrieved from http://www.theguardian.com/books/2012/jul/06/margaret-atwood-wattpadonline-writing.

Balaram, B. (2016). Fair Share: Reclaiming power in the sharing economy. RSA available at https://medium.com/@thersa/fair-share-reclaiming-power-inthe-sharing-economy-499b46bd4b00\#.klx0etam9.

Bauwens, M. (2005). The political economy of peer production. CTheory. Retrieved from http://www.ctheory.net/articles.aspx?id=499.

Benkler, Y. (2006). The Wealth of Networks: How Social Production Transforms Markets and Freedom. Yale University Press. Creative Commons version. Retrieved from http://cyber.law.harvard.edu/wealth_of_networks/ Download_PDFs_of_the_book.

Berlant, L. (1997). The Queen of America Goes to Washington City. Durham, NC: Duke University Press.

. (2008). The Female Complaint: The Unfinished Business of Sentimentality in American Culture. Durham, NC: Duke University Press.

Black, R. W. (2008). Adolescents and Online Fan Fiction. New York, NY: Peter Lang.

Bloomsbury (2016). Book groups. Retrieved from http://www.bloomsbury. com/uk/communities/book-groups.

Boltanski, L. \& Chiapello, E. (2005 [1999]) (Translated by Gregory Elliott). The New Spirit of Capitalism. London: Verso.

Botsman, R. \& Rogers, R. (2011). What's Mine is Yours: How Collaborative Consumption is Changing the Way We Live [Kindle Version] Retrieved from www.amazon.co.uk.

boyd, d. (2014). It's Complicated: The Social Lives of Networked Teens. New Haven, CT: Yale University Press.

Brouillette, S. (2014). Literature and the Creative Economy. Stanford, CA: Stanford University Press. 
Burgess, J. and Green, J. (2009). YouTube: Online Video and Participatory Culture, Cambridge: Polity Press.

Campbell, L. (2015) Hachette chiefs dismiss subscription model. The Bookseller, 2 April. Retrieved from http://www.thebookseller.com/news/hachettechiefs-dismiss-subscription-model.

Couldry, N. (2010). Why Voice Matters: Culture and Politics after Neoliberalism. London: SAGE.

Davies, W. (2015). The Happiness Industry: How the Government and Big Business Sold us Well-Being. London: Verso.

Dredge, S. (2015). YouTube stars Ryan Higa and the Young Turks launch 'superfan' mobile apps. The Guardian, 23 April. Retrieved from http://www. theguardian.com/technology/2015/apr/23/youtube-ryan-higa-the-youngturks-apps.

Gardner, A. (interviewee) (2014) How to use Wattpad as an author with Ashleigh Gardner. The Creative Penn, 31 January [Audio Podcast]. Retrieved from http://www.thecreativepenn.com/2014/01/31/wattpad.

Groskop, V. (2014/15). Jam Sessions. Mslexia, Issue 64 DEC/JAN/FEB

Hind, D. (2010). The Return of the Public. London: Verso.

Hipes, P. (2015). Wattpad inks deal with UTA amid 'after' success. Deadline, 15 October. Retrieved from http://deadline.com/2015/10/wattpad-movies-tvhollywood-uta-1201584126.

Jenkins, H. et al. (2013). Spreadable Media: Creating Value and Meaning in a Networked Culture. New York: New York University Press [Kindle Version] Retrieved from amazon.co.uk.

Kirci, H (2014). The tales teens tell: What Wattpad did for girls. The Guardian, 16 April. Retrieved from http://www.theguardian.com/technology/2014/ aug/16/teen-writing-reading-wattpad-young-adults

Lau, A (interviewee) (2013). Ancient art updated. Beyond the Book, 28 July [Audio Podcast]. Retrieved from http://beyondthebookcast.com/ancientart-updated.

Lindin, E (2013) The Unslut Project: How sexual bullying ruined my childhood. The Guardian, 21 September. Retrieved from http://www.theguardian.com/society/2013/sep/21/unslut-project-against-sexual-bullying.

Martin, T (2016). Why Julian Fellowes's new app Belgravia won't start a revolution. The Telegraph, 16 April. Retrieved from http://www.telegraph.co.uk/ books/what-to-read/why-julian-fellowess-new-app-belgravia-wont-starta-revolution.

Nawotka, E (2015). Content licensing is key to Wattpad's future. Publishing Perspectives, 6 August. Retrieved from http://publishingperspectives. com/2015/08/content-licensing-is-key-to-wattpads-future/\#.VtMTGdAjhJF.

Owens, T.J. (2014). Designing online communities: How designers, developers, community managers, and software structure discourse and knowledge production on the web. PhD Thesis. George Mason University 
Penguin (2016). Book clubs. Retrieved from http://www.penguin.com/read/ book-clubs/

Phillips, A. (2016) The wisdom of crowds: Crowdfunding and crowdsourcing 12 April, London Book Fair Workshop.

Plant, R. (1990) Communities v. Consumers. The Times, 28 August available from Lexis Nexis

Powell, C. (2013). How one direction helped make Wattpad a bestseller. Marketing, July 24. Retrieved from http://www.marketingmag.ca/media/howone-direction-helped-make-wattpad-a-bestseller-84417.

Preston, P. (2005 ). There is no such thing as community: The idea that society comprises homogeneous groups is deluded. The Guardian, 18 July available from Lexis Nexis

Romano, A. (2012). Wattpad's unlikely literary revolution. Daily Dot, 25 July. Retrieved from http://www.dailydot.com/business/wattpad-unlikelyliterary-revolution/

Thompson, J. (2012). Merchants of Culture: The Publishing Business in the Twenty-First Century ( $2^{\text {nd }}$ Ed). Cambridge: Polity Press.

Tomada, N. (2014). Wattpad stories come alive on TV5. The Philippine Star, 22 September. Retrieved from www.philstar.com/entertainment/2014/09/22/1371641/wattpad-stories-come-alive-tv5.

Troncoso, S. (2016). Douglas Rushkoff's vision for a new, better world. P2P Foundation, 15 March. Retrieved from https://blog.p2pfoundation.net/ douglas-rushkoffs-vision-new-better-world/2016/03/15.

Unslut Project, The. Retrieved from http://www.unslutproject.com.

Wattpad (2016a). About Wattpad. Retrieved from https://www.wattpad.com/ press.

. (2016b). The Unslut Project: How a private diary became a social movement. Retrieved from http://blog.wattpad.com/2016/02/26/the-unslut-projecthow-a-private-diary-became-a-social-movement.

. (2016c). How do I promote my story? Retrieved from https://support. wattpad.com/hc/en-us/articles/201415550-How-do-I-Promote-my-Story. (2016d). How Wattpad Works. Retrieved from https://www.wattpad. com/168209788-how-wattpad-works-how-to-wattpad.

. (2016e). Partnerships. Retrieved from http://blog.wattpad.com/category/ partnerships.

. (2016f). Brand stories. Retrieved from http://business.wattpad.com.

Wilting Hope. (2015). School spirit. Chapter 1. The summer is breaking up with me [Comment]. Wattpad, 22 July. Retrieved from https://www.wattpad. com/79301784-school-spirit-book-1-1-the-summer-is-breaking-up/page/4. 
